\title{
Noninvasive ventilation improves cardiac function in patients with chronic heart failure
}

\author{
Jing Cheng ${ }^{1}$, Yanping Liu ${ }^{1,2}$, Guishuang $\mathbf{L i}^{1}$, Zhongwen Zhang ${ }^{3}$, Lianyue Ma ${ }^{1}$, \\ Xiaoyan Yang ${ }^{1}$, Jianmin Yang ${ }^{1}$, Kai Zhang ${ }^{1}$, Jing Kong ${ }^{1}$, Mei Dong ${ }^{1}$, Meng Zhang ${ }^{1}$, \\ Xingli Xu ${ }^{1}$, Wenhai Sui ${ }^{1}$, Jiali Wang ${ }^{1}$, Rui Shang ${ }^{1}$, Xiaoping $\mathrm{Ji}^{1}$, Yun Zhang ${ }^{1}$, Cheng \\ Zhang ${ }^{1}$ and Panpan Hao ${ }^{1}$ \\ 1 The Key Laboratory of Cardiovascular Remodeling and Function Research, Chinese Ministry of Education and Chinese \\ Ministry of Health, Shandong University Qilu Hospital, Jinan, Shandong, China \\ ${ }^{2}$ Shandong Key Laboratory of Cardiovascular and Cerebrovascular Disease, Shandong Provincial Medical Imaging Institute, \\ Shandong University, Jinan, Shandong, China \\ ${ }^{3}$ Shandong Provincial Qianfoshan Hospital, Shandong University, Jinan, Shandong, China \\ Correspondence to: Panpan Hao, email: panda.how@126.com \\ Keywords: noninvasive ventilation, chronic heart failure, sleep-disordered breathing, left ventricular ejection fraction, brain natri- \\ uretic peptide, Pathology Section \\ Received: April 15, $2016 \quad$ Accepted: June 17, $2016 \quad$ Published: July 06, 2016
}

\section{ABSTRACT}

Chronic heart failure (CHF) has been shown to be associated with an increased incidence of sleep-disordered breathing. Whether treatment with noninvasive positivepressure ventilation (NPPV), including continuous positive airway pressure, bi-level positive airway pressure and adaptive servo-ventilation, improves clinical outcomes of CHF patients is still debated. 2,832 CHF patients were enrolled in our analysis. NPPV was significantly associated with improvement in left ventricular ejection fraction (39.39\% vs. 34.24\%; WMD, 5.06; 95\% CI, 3.30-6.81; $P<0.00001$ ) and plasma brain natriuretic peptide level $(268.23 \mathrm{pg} / \mathrm{ml}$ vs. $455.55 \mathrm{pg} / \mathrm{ml}$; WMD, $-105.66 ; 95 \% \mathrm{CI}$, [-169.19]-[-42.13]; $P=0.001)$. However, NPPV did not reduce all-cause mortality (0.26\% vs. $0.24 \%$; OR, $1.13 ; 95 \% \mathrm{CI}, 0.93-1.37 ; P=0.22)$ or re-hospitalization rate $(57.86 \%$ vs. $59.38 \%$; OR, $0.47 ; 95 \% C I, 0.19-1.19 ; P=0.02)$ as compared with conventional therapy. Despite no benefits on hard endpoints, NPPV may improve cardiac function of CHF patients. These data highlight the important role of NPPV in the therapy of CHF.

\section{INTRODUCTION}

Sleep-disordered breathing (SDB), including Cheyne-Stokes respiration with central sleep apnea (CSR-CSA) and obstructive sleep apnea (OSA), is highly prevalent in patients with chronic heart failure (CHF). Large scale studies revealed that the prevalence of SDB in CHF patients is about $69 \% \sim 76 \%$ [1]. CHF patients with CSA might be suffering from greater augmented sympathetic nervous activity (SNA) than those without CSA [2]. Activated SNA increases peripheral vascular resistance and cardiac load, thus, exacerbating prognosis and remodeling cardiac structure. SDB is usually treated with noninvasive positive pressure ventilation (NPPV), which includes continuous positive airways pressure
(CPAP), bi-level positive airway pressure (Bi-PAP) and adaptive servo-ventilation (ASV). NPPV can improve respiratory disturbances to different degree, and thereafter reduce venous return, cardiac preload and pulmonary congestion [3-5]. NPPV has been recommended and widely used in the respiratory management of patients with acute heart failure (AHF) [6, 7]. Although NPPV has been confirmed to improve the hemodynamics in AHF inpatients, this therapy in CHF outpatients was controversial $[8,9]$.

Drug therapy, mainly including angiotensinconverting enzyme (ACE) inhibitors, angiotensin II receptor blockers (ARBs) and $\beta$-blockers, has substantially improved the prognosis of patients with mild to moderate CHF, but the prognosis of patients with severe CHF remains poor. Hence, novel nonpharmacotherapy such 
Table 1: Results of clinical events and cardiac function

\begin{tabular}{|l|l|l|l|l|l|l|}
\hline Outcomes & References & Patients & OR/WMD $\mathbf{( 9 5 \%}$ CI) & $\boldsymbol{P}$ value & $\mathbf{I}^{\mathbf{2}} \boldsymbol{\%} \%$ & $\begin{array}{l}\text { Heterogeneity } \\
\boldsymbol{P} \text { value }\end{array}$ \\
\hline Mortality & $\begin{array}{l}10,11,15- \\
17,19,23,27,31\end{array}$ & 2311 & $1.13[0.93,1.37]$ & $P=0.22$ & $48 \%$ & $P=0.05$ \\
\hline Re-hospitalization rate & $14-16,31$ & 1612 & $0.47[0.19,1.19]$ & $P=011$ & $68 \%$ & $P=0.02$ \\
\hline LVEF & $\begin{array}{l}3,10,12,14,15,18- \\
22,24-26,28-31\end{array}$ & 785 & $5.06[3.30,6.81]$ & $P<0.00001$ & $82 \%$ & $P<0.00001$ \\
\hline BNP & $3,15,30,31$ & 367 & $-105.66[-169.19,-42.13]$ & $P=0.001$ & $34 \%$ & $P=0.21$ \\
\hline
\end{tabular}

BNP, brain natriuretic peptide; CI, confidence interval; LVEF, left ventricular ejection fraction; OR, odds ratio; WMD, weighted mean difference.

as NPPV that might extend life expectancy and improve quality of life of CHF patients is required. However, studies focusing on effects of NPPV on CHF prognosis were limited by small sample size and inconclusive. Thus, we used powerful pooled-analysis methodology to investigate the impact of NPPV on all-cause mortality, re-hospitality and cardiac function in CHF patients, regardless of breathing status during sleeping.

\section{RESULTS}

We identified 8,869 potentially eligible literature citations, of which 56 were reviewed as full articles. Only 23 reports of studies with suitable data were eligible for inclusion, all of which were full articles published in English from 1997 to 2015 [3, 10-31]. A total of 2,832 subjects were enrolled in the pooled analysis, of which 2,408 were from 15 randomized control trials (RCTs) [10-24] and 424 from 8 observational studies [3, 25-31]. The interobserver agreement for the study selection was excellent $(\kappa=0.91)$.

The sample sizes ranged from 14 to 1,325 participants. The mean ages of the study participants ranged from 56.9 to 72.8 years and the mean follow-up from 1 to 24 months. The methodological quality of the included studies was in general poor, with only 9 of 23 reports describing two or more of the four quality criteria. Loss to follow-up was reported as $<10 \%$ in only 16 reports.

\section{Clinical end-points}

Cardiovascular events as well as cardiac function were evaluated for all 23 studies (Table 1). Although NPPV did not differ from conventional therapy in reducing all-cause mortality $(0.26 \%$ vs. $0.24 \%$; pooled odds ratio [OR], 1.13; 95\% confidence interval [CI], 0.93 $1.37 ; P=0.22)$ or re-hospitality $(57.86 \%$ vs. $59.38 \%$; OR, $0.47 ; 95 \%$ CI, $0.19-1.19 ; P=0.02$ ), it significantly reduced left ventricular ejection fraction (LVEF) $(39.39 \%$ vs. $34.24 \%$ ) with a pooled weighted mean difference (WMD) of 5.06 (95\% CI, 3.30-6.81; $P<0.00001)$ and plasma brain natriuretic peptide (BNP) level (268.23 $\mathrm{pg} / \mathrm{ml}$ vs. $455.55 \mathrm{pg} / \mathrm{ml})$ with a WMD of $-105.66(95 \%$ CI, [-169.19]- [-42.13]; $P=0.001)$ as compared with conventional therapy in CHF patients.

\section{Sensitivity/subgroup analysis}

For the sensitivity analysis, removal of the largest study [16] produced no significant alterations in pooled WMDs/ORs, indicating that the results of our pooled analysis were statistically reliable.

Heterogeneity was addressed well in the analyses of all-cause mortality $\left(I^{2}=48 \%\right)$ and plasma BNP level $\left(I^{2}=\right.$ $34 \%)$. However, high heterogeneity existed in the analyses of LVEF $\left(I^{2}=82 \%\right)$ and re-hospitality $\left(I^{2}=68 \%\right)$. After removal of one study [24] from the analysis of LVEF, the heterogeneity was significantly decreased to $30 \%$ (WMD 3.59, favoring NPPV; 95\% CI, 2.47-4.70; $P<0.00001$ ). Thereafter, we performed subgroup analyses in terms of LVEF (Table 2). The between-study heterogeneity was explained in part by the variability in concomitant breathing status during sleeping, NPPV subtypes and follow-up duration, but not by study design or race.

\section{Fail-safe number (Nfs)}

We calculated the $\mathrm{Nfs} 0.05$ for each comparison and found the $\mathrm{N}_{\mathrm{fs} 0.05}$ values for all-cause mortality, rehospitality, LVEF and plasma BNP to be greater than the numbers of studies included in the analyses. However, the $\mathrm{N}_{\mathrm{fs} 0.05}$ value for cardiovascular death was smaller than the number of retrieved studies, which was possibly consistent with small-study-related bias.

\section{DISCUSSION}

The results indicated that NPPV was more efficacious in decreasing LVEF and plasma BNP level than conventional therapy in CHF outpatients, though it did not exhibit significant effect on the all-cause death and re-hospitalization. The pathophysiological features of this effect remain to be elucidated. 
Table 2: Subgroup analyses with regard to the risk of LVEF

\begin{tabular}{|c|c|c|c|c|c|c|}
\hline Subgroup & Studies & Patients, $n$ & WMD (95\% CI) & $P$ value & $I^{2}, \%$ & $\begin{array}{l}\text { Heterogeneity } \\
P \text { value }\end{array}$ \\
\hline \multicolumn{7}{|c|}{ Adjustment for study design } \\
\hline RCTs & $10,14,15,18-22,24,25,28$ & 567 & $4.13[2.01,6.24]$ & $P<0.00001$ & $82 \%$ & $P<0.00001$ \\
\hline Observational studies & $3,12,26,29-31$ & 218 & $6.84[3.11,10.57]$ & $P=0.0002$ & $80 \%$ & $P<0.0004$ \\
\hline \multicolumn{7}{|l|}{ Adjustment for race } \\
\hline Caucasian & $10,19-22,24-26,28,29$ & 345 & $4.36[2.34,6.38]$ & $P<0.00001$ & $84 \%$ & $P<0.00001$ \\
\hline Asian & $3,12,14,15,18,30,31$ & 440 & $6.43[2.41,10.45]$ & $P<0.002$ & $77 \%$ & $P<0.0003$ \\
\hline \multicolumn{7}{|c|}{ Adjustment for breathing status during sleeping } \\
\hline CSR-CSA & $14,19,26,29-31$ & 167 & $6.68[2.54,10.82]$ & $P=0.002$ & $79 \%$ & $P=0.0002$ \\
\hline OSA & $22,24,25,28$ & 110 & $6.68[5.20,8.16]$ & $P<0.00001$ & $13 \%$ & $P=0.33$ \\
\hline SDB & $3,10,12,18,20,21$ & 303 & $3.03[1.12,4.94]$ & $P=0.002$ & $35 \%$ & $P=0.17$ \\
\hline Unclear & 15 & 205 & $1.70[-1.27,4.67]$ & $P=0.26$ & NA & NA \\
\hline \multicolumn{7}{|c|}{ Adjustment for NPPV subtypes } \\
\hline CPAP & $21,22,24-26,28,29$ & 211 & $3.56[3.01,4.10]$ & $P<0.00001$ & $88 \%$ & $P<0.00001$ \\
\hline Bi-PAP & 30 & 14 & $13.50[9.71,17.29]$ & $P<0.00001$ & & NA \\
\hline ASV & $3,10,12,14,15,18-20,31$ & 560 & $3.06[1.39,4.74]$ & $P=0.0003$ & $3 \%$ & $P=0.41$ \\
\hline \multicolumn{7}{|c|}{ Adjustment for follow-up duration } \\
\hline$>3$ month & $3,14,15,18,31$ & 411 & $3.48[1.45,5.52]$ & $P=0.0008$ & $15 \%$ & $P=0.32$ \\
\hline$\leq 3$ month & $10,12,19-22,24-26,28,30$ & 374 & $3.71[3.18,4.24]$ & $P<0.00001$ & $87 \%$ & $P<0.00001$ \\
\hline
\end{tabular}

ASV, adaptive servo-ventilation; Bi-PAP, bi-level positive airway pressure; CI, confidence interval; CPAP, continuous positive airways pressure; CSR-CSA, Cheyne-Stokes respiration with central sleep apnea; LVEF, left ventricular ejection fraction; OSA, obstructive sleep apnea; SDB: Sleep-disordered breathing; RCTs, randomized controlled trials; WMD, weighted mean difference.

Stable CHF has been shown to be associated with an increased incidence of SDB, especially CSA. CHF patients develop CSA during both wakefulness and sleep, which typically demonstrate baseline hypocapnia [32, 33]. Hypocapnia from hyperventilation may be due to chronic interstitial pulmonary congestion, stimulating the pulmonary vagal reflex [34] or from the hypoxemic ventilatory response [35]. The coexistence of SDB and $\mathrm{CHF}$ is associated with poor survival. CSA decreases oxygen saturation and increases muscular SNA in CHF patients [36]. This additional stimulus to sympathetic nerve may accelerate the progression of CHF. A wealth of evidence has demonstrated that inhibition of a hyperactive SNA by ACE inhibitors, ARBs or $\beta$-blockers protects against LV remodeling and heart failure. Furthermore, we have found that ACE2 and Ang-(1-7), 2 new components of renin-angiotensin system, mitigate diabetic cardiomyopathy [37-39]. Sympathetic-inhibitory effect of NPPV might play a critical role in the treatment of CHF.

With respect to OSA, negative intra-thoracic pressure is exaggerated by inspiratory efforts against the occluded pharynx. It increases not only the right ventricle preload but also the right ventricular afterload. Negative intrathoracic pressure could increase death caused by cardiovascular events $[40,41]$. CPAP has been reported to reduce the severity of SDB, improve exercise capacity, and improve cardiac function [11, 12, 42]. Effective CPAP reduced respiratory disturbances and cardiac haemodynamic parameters such as systolic/diastolic blood pressure. Furthermore, it improved cardiovascular neurohumoral function, sympathetic markers and quality of life [43]. It is well recognized that ASV is described as the most effective alternative for CSR-CSA in CHF patients [25]. A recent meta-analysis showed that chronic ASV therapy improved cardiac function in CHF with SDB [44]. Our data indicated NPPV therapy mitigated cardiac dysfunction in CHF patients, regardless of breathing status during sleeping. NPPV may improve cardiac function through increasing oxygen saturation, as well as decreasing SNA and blood pressure.

NPPV is a well established and increasingly used therapeutic option to treat patients with chronic hypercapnic respiratory failure that arises from different etiologies [45]. In cardio-respiratory disorders, NPPV is commonly used in treatments of AHF, chronic obstructive pulmonary disease, obesity hypoventilation syndrome, cystic fibrosis and neuromuscular disorders. Nowadays, various modes of NPPV have been investigated to treat CHF. The initial use of NPPV is CPAP, addressing the common component of increased upper airway resistance and obstruction. It also provide additional benefits of blood pressure reduction and decreased cardiac transmural pressure, thereby decreasing preload and afterload and improving LVEF [46]. However, patients using CPAP arise some side effects. Some studies showed potential hypovolemic effect with CPAP by decreased filling 
pressures in such patients $[47,48]$. Bi-PAP in patients with CSR-CSA and CHF might improve apnea hypoventilation index, sleep quality and LVEF compared with Non-PAP or CPAP $[26,49,50]$. ASV is designed to average antecedent direction, magnitude and rate of change of airflow, providing inspiratory positive airway pressure support that varies dynamically according to the sensed patient airflow, essentially resulting in complementary ventilatory support appropriate to the patients' alternating hyperpneas and hypopneas. ASV use in CHF patients may improve physiologic parameters and reduce adverse cardiovascular events [13]. Even, ASV has also been used to treat CSRCSA in CHF patients with preserved ejection fraction [51]. ASV significantly reduced the severity of sleep apnea, especially producing a better elimination of CSA than CPAP, and counteracted hypoxia to prevent subsequent inflammatory responses [52].

Several limitations should be considered in interpreting our results. First, high heterogeneity existed in analyses of re-hospitalization rate and LVEF. The pooled analysis had significant disparity in sample sizes of the studies considered. In fact, among the 2,952 patients included in the analysis, 1,325 (44.9\%) were from Cowie et al study [14]. However, after removing data of this study, we found nosubstantial alteration in pooled ORs/ WMDs. Second, the sample sizes of some studies were small and the smallest study only enrolled 14 patients [26]. However, the decision to include small-sample studies was necessary to maximize the utilization of all available data on this important topic. Third, the different results between hard endpoints (death and rehospitalization) and surrogate endpoints (BNP and LVEF) might be attributed to the relatively short follow-up durations. The follow-ups were relatively short, and that was 24 months in one study, 12 months in 3 studies, 6 months in 5 studies and $<6$ months in the other studies. Thus, more large-scale, multinational, multicenter, randomized, controlled and long term followup trials are warranted.

\section{MATERIALS AND METHODS}

\section{Data sources, search strategy, and selection criteria}

We performed a systematic computerized search of MEDLINE, EMBASE, Web of science and Cochrane databases to identify clinical trials assessing effects of NPPV treatments (CPAP, Bi-PAP, and ASV) on clinical outcomes in $\mathrm{CHF}$ patients. Bibliographies of retrieved articles, previous pooled analysis, and reviews were also used to identify any potentially relevant publications miss in our search. We had no restriction on language or whether the results had been published.

Literatures were searched in MEDLINE with the terms ("ASV" or "adaptive servo ventilation" or "adaptive ventilation" or "servoventilation" or "Bi-PAP" or "bilevel positive airway pressure" or "CPAP" or "continuous positive airway pressure" or "noninvasive ventilation" [MeSH Terms] AND ("heart failure" or "chronic heart failure") with no restriction on subheadings (up to 24 March, 2016). Similar but adapted search terms were used for the other literature databases or search engines. In order to increase sample size, widen population coverage and increase statistical power, we included results for both RCTs and observational studies.

The study selection criteria were as follows: (i) compared NPPV treatment (CPAP, Bi-PAP or ASV) vs. control group without NPPV in patients with diagnosis of stable CHF; (ii) were RCTs or observational studies with at least a 1-month follow-up for each group; and (iii) contained sufficient information to estimate the pooled WMDs or the pooled ORs and their corresponding 95\% CIs.

\section{Data extraction}

The following information was extracted from published reports by use of a standardized protocol: first author's last name, year of publication, study design, country of origin, number of enrolled patients, subject characteristics at baseline (age, sex, LVEF, family history of cardiovascular disease, NYHA Class), follow-up duration, concomitant medication, and end-points.

\section{Quality assessment}

The methodological quality of eligible studies was assessed with criteria adapted from guidelines for the evaluation of articles on prognosis [53]. he literature search, data extraction and quality assessment were undertaken independently and blindly by two authors (J.C. and Y.P.L.) using a standardized approach. Any disagreements were resolved by a third reviewer (P.P.H.).

\section{Statistical analysis}

RevMan 5.3 software, developed by the Cochrane Collaboration (http://www.cc-ims.net/revman, accessed on 16 November 2015) was used for the pooled analysis. The between-study heterogeneity was tested by the chi-squarebased Cochran's Q statistic and the inconsistency index $\left(\mathrm{I}^{2}\right)$. Statistically significant heterogeneity was considered with a chi-square $P<0.10$ and $I^{2}>50 \%$. Results showing no significant heterogeneity were analyzed by the fixedeffects model and those with significant heterogeneity were analyzed by the random-effects model. Pooled WMDs or ORs were reported with $95 \%$ CIs, and a twotailed $P<0.05$ was considered statistically significant for 
all analyses. In addition, sensitivity or subgroup analyses were conducted to seek more narrowly drawn subsets of reports of studies by removing an individual study each time or studies with similar features to assess individual effects. Finally, we assessed publication bias using Nfs. Any calculated Nfs value smaller than the number of retrieved reports of studies indicated publication bias. We calculated the $\mathrm{N}_{\mathrm{fs} 0.05}$ as $\mathrm{N}_{\mathrm{fs} 0.05}=\left(\sum \mathrm{Z} / 1.64\right)^{2}-\mathrm{k}$, where $\mathrm{k}$ is the number of reports of studies included in the analysis.

\section{ACKNOWLEDGMENTS}

This work was supported by the National 973 Basic Research Program of China (grants 2011CB503906, 2012CB518603), the National High-Tech Research and Development Program of China (grant 2012AA02A510), the Program of Introducing Talents of Discipline to Universities (grant B07035), the State Program of National Natural Science Foundation of China for Innovative Research Group (grant 81021001), the National Natural Science Foundation of China (grants 81400284, $81530014,81371548,81320108004,61331001)$, the Natural Science Foundation of Shandong Province (grants ZR2014HM044, ZR2014HP045) and the Clinical Medicine Science and Technology Innovation Plan of Jinan Science \& technology Bureau (Grant 201506002).

\section{CONFLICTS OF INTEREST}

There is no conflict of interest.

\section{REFERENCES}

1. Wang H, Parker JD, Newton GE, Floras JS, Mak S, Chiu KL, Ruttanaumpawan P, Tomlinson G, and Bradley TD. Influence of obstructive sleep apnea on mortality in patients with heart failure. Journal of the American College of Cardiology. 2007; 49: 1625-31.

2. Kasai T, Kasagi S, Maeno K, Dohi T, Kawana F, Kato M, Naito R, Ishiwata S, Ohno M, Yamaguchi T, Narui K, and Momomura S. Adaptive servo-ventilation in cardiac function and neurohormonal status in patients with heart failure and central sleep apnea nonresponsive to continuous positive airway pressure. JACC Heart failure. 2013; 1: 5863.

3. Koyama T, Watanabe H, Igarashi G, Terada S, Makabe $\mathrm{S}$, and Ito $\mathrm{H}$. Short-term prognosis of adaptive servoventilation therapy in patients with heart failure. Circ J. 2011; 75: 710-2.

4. Fietze I, Blau A, Glos M, Theres H, Baumann G, and Penzel T. Bi-level positive pressure ventilation and adaptive servo ventilation in patients with heart failure and Cheyne-Stokes respiration. Sleep medicine. 2008; 9: 652-9.

5. Mehta S, and Hill NS. Noninvasive ventilation. American journal of respiratory and critical care medicine. 2001; 163 : 540-77.

6. JCS Joint Working Group. Guidelines for treatment of acute heart failure (JCS 2011). Circ J. 2013; 77: 2157-201.

7. Golmard C. [Non-invasive ventilation and acute cardiogenic pulmonary oedema]. [Article in French] Revue de l'infirmiere. 2015; 215: 41-3.

8. Spiesshofer J, Heinrich J, Bitter T, Efken C, Lehmann R, Eckert S, Horstkotte D, and Oldenburg O. Validation of blood pressure monitoring using pulse transit time in heart failure patients with Cheyne-Stokes respiration undergoing adaptive servoventilation therapy. Sleep Breath. 2014; 18: 411-21.

9. Oldenburg O, Bitter T, Lehmann R, Korte S, Dimitriadis Z, Faber L, Schmidt A, Westerheide N, and Horstkotte D. Adaptive servoventilation improves cardiac function and respiratory stability. Clin Res Cardiol. 2011; 100: 107-15.

10. Arzt M, Schroll S, Series F, Lewis K, Benjamin A, Escourrou P, Luigart R, Kehl V, and Pfeifer M. Autoservoventilation in heart failure with sleep apnoea: a randomised controlled trial. The European respiratory journal. 2013; 42: 1244-54.

11. Arzt M, Floras JS, Logan AG, Kimoff RJ, Series F, Morrison D, Ferguson K, Belenkie I, Pfeifer M, Fleetham J, Hanly P, Smilovitch M, Ryan C, Tomlinson G, Bradley TD, and Investigators C. Suppression of central sleep apnea by continuous positive airway pressure and transplant-free survival in heart failure: a post hoc analysis of the Canadian Continuous Positive Airway Pressure for Patients with Central Sleep Apnea and Heart Failure Trial (CANPAP). Circulation. 2007; 115: 3173-80.

12. Mansfield DR, Gollogly NC, Kaye DM, Richardson M, Bergin P, and Naughton MT. Controlled trial of continuous positive airway pressure in obstructive sleep apnea and heart failure. American journal of respiratory and critical care medicine. 2004; 169: 361-6.

13. Yoshihisa A, Suzuki S, Yamaki T, Sugimoto K, Kunii H, Nakazato K, Suzuki H, Saitoh S, and Takeishi Y. Impact of adaptive servo-ventilation on cardiovascular function and prognosis in heart failure patients with preserved left ventricular ejection fraction and sleep-disordered breathing. European journal of heart failure. 2013; 15: 543-50.

14. Cowie MR, Woehrle H, Wegscheider K, Angermann C, d'Ortho MP, Erdmann E, Levy P, Simonds AK, Somers VK, Zannad F, and Teschler H. Adaptive Servo-Ventilation for Central Sleep Apnea in Systolic Heart Failure. The New England journal of medicine. 2015; 373: 1095-105.

15. Miyata M, Yoshihisa A, Suzuki S, Yamada S, Kamioka M, Kamiyama Y, Yamaki T, Sugimoto K, Kunii H, Nakazato K, Suzuki H, Saitoh S, and Takeishi Y. Adaptive servo ventilation improves Cheyne-Stokes respiration, cardiac function, and prognosis in chronic heart failure patients with cardiac resynchronization therapy. Journal of cardiology. 2012; 60: 222-7. 
16. Momomura S, Seino Y, Kihara Y, Adachi H, Yasumura Y, Yokoyama H, Wada H, Ise T, and Tanaka K. Adaptive servo-ventilation therapy for patients with chronic heart failure in a confirmatory, multicenter, randomized, controlled study. Circ J. 2015; 79: 981-90.

17. Hetland A, Haugaa KH, Olseng M, Gjesdal O, Ross S, Saberniak J, Jacobsen MB, and Edvardsen T. Three-month treatment with adaptive servoventilation improves cardiac function and physical activity in patients with chronic heart failure and cheyne-stokes respiration: a prospective randomized controlled trial. Cardiology. 2013; 126: 81-90.

18. Birner C, Series F, Lewis K, Benjamin A, Wunderlich S, Escourrou P, Zeman F, Luigart R, Pfeifer M, and Arzt M. Effects of auto-servo ventilation on patients with sleep-disordered breathing, stable systolic heart failure and concomitant diastolic dysfunction: subanalysis of a randomized controlled trial. Respiration. 2014; 87: 54-62.

19. Egea CJ, Aizpuru F, Pinto JA, Ayuela JM, Ballester E, Zamarron C, Sojo A, Montserrat JM, Barbe F, AlonsoGomez AM, Rubio R, Lobo JL, Duran-Cantolla J, et al. Cardiac function after CPAP therapy in patients with chronic heart failure and sleep apnea: a multicenter study. Sleep medicine. 2008; 9: 660-6.

20. Gilman MP, Floras JS, Usui K, Kaneko Y, Leung RS, and Bradley TD. Continuous positive airway pressure increases heart rate variability in heart failure patients with obstructive sleep apnoea. Clinical science (London, England: 1979). 2008; 114: 243-9.

21. Bradley TD, Logan AG, Kimoff RJ, Series F, Morrison D, Ferguson K, Belenkie I, Pfeifer M, Fleetham J, Hanly P, Smilovitch M, Tomlinson G, and Floras JS. Continuous positive airway pressure for central sleep apnea and heart failure. The New England journal of medicine. 2005; 353: 2025-33.

22. Ruttanaumpawan P, Gilman MP, Usui K, Floras JS, and Bradley TD. Sustained effect of continuous positive airway pressure on baroreflex sensitivity in congestive heart failure patients with obstructive sleep apnea. Journal of hypertension. 2008; 26: 1163-8.

23. Sin DD, Logan AG, Fitzgerald FS, Liu PP, and Bradley TD. Effects of continuous positive airway pressure on cardiovascular outcomes in heart failure patients with and without Cheyne-Stokes respiration. Circulation. 2000; 102: 61-6.

24. Ryan CM. Effect of continuous positive airway pressure on ventricular ectopy in heart failure patients with obstructive sleep apnoea. Thorax. 2005; 60: 781-5.

25. Koyama T, Watanabe H, Kobukai Y, Makabe S, Munehisa Y, Iino K, Kosaka T, and Ito H. Beneficial Effects of Adaptive Servo Ventilation in Patients With Chronic Heart Failure. Circulation Journal. 2010; 74: 2118-24.

26. Kasai T, Narui K, Dohi T, Ishiwata S, Yoshimura K, Nishiyama S, Yamaguchi T, and Momomura S. Efficacy of nasal bi-level positive airway pressure in congestive heart failure patients with cheyne-stokes respiration and central sleep apnea. Circ J. 2005; 69: 913-21.

27. Koyama T, Watanabe H, Igarashi G, Tamura Y, Ikeda K, Terada S, and Ito H. Effect of short-duration adaptive servoventilation therapy on cardiac function in patients with heart failure. Circ J. 2012; 76: 2606-13.

28. Takama N, and Kurabayashi M. Effect of Adaptive ServoVentilation on 1-Year Prognosis in Heart Failure Patients. Circulation Journal. 2012; 76: 661-7.

29. Arzt M, Schulz M, Wensel R, Montalvan S, Blumberg FC, Riegger GA, and Pfeifer M. Nocturnal continuous positive airway pressure improves ventilatory efficiency during exercise in patients with chronic heart failure. Chest. 2005; 127: 794-802.

30. Tkacova R, Liu PP, Naughton MT, and Bradley TD. Effect of continuous positive airway pressure on mitral regurgitant fraction and atrial natriuretic peptide in patients with heart failure. Journal of the American College of Cardiology. 1997; 30: 739-45.

31. Yoshihisa A, Shimizu T, Owada T, Nakamura Y, Iwaya S, Yamauchi H, Miyata M, Hoshino Y, Sato T, Suzuki S, Sugimoto K, Yamaki T, Kunii H, et al. Adaptive servo ventilation improves cardiac dysfunction and prognosis in chronic heart failure patients with Cheyne-Stokes respiration. International heart journal. 2011; 52: 218-23.

32. Hanly P, Zuberi N, and Gray R. Pathogenesis of CheyneStokes respiration in patients with congestive heart failure. Relationship to arterial PCO2. Chest. 1993; 104: 1079-84.

33. Lorenzi-Filho G, Rankin F, Bies I, and Douglas Bradley T. Effects of inhaled carbon dioxide and oxygen on cheynestokes respiration in patients with heart failure. American journal of respiratory and critical care medicine. 1999; 159: 1490-8.

34. Glogowska M, and Widdicombe JG. The role of vagal reflexes in experimental lung oedema, bronchoconstriction and inhalation of halothane. Respiration physiology. 1973; 18: 116-28.

35. Fanfulla F, Mortara A, Maestri R, Pinna GD, Bruschi C, Cobelli F, and Rampulla C. The development of hyperventilation in patients with chronic heart failure and Cheyne-Strokes respiration: a possible role of chronic hypoxia. Chest. 1998; 114: 1083-90.

36. Bradley TD, and Floras JS. Sleep apnea and heart failure: Part II: central sleep apnea. Circulation. 2003; 107: 1822-6.

37. Dong B, Yu QT, Dai HY, Gao YY, Zhou ZL, Zhang L, Jiang H, Gao F, Li SY, Zhang YH, Bian HJ, Liu CX, Wang N, Xu H, Pan CM, Song HD, Zhang C, Zhang Y. Angiotensin-converting enzyme-2 overexpression improves left ventricular remodeling and function in a rat model of diabetic cardiomyopathy. J Am Coll Cardiol. 2012; 59: 73947.

38. Hao PP, Yang JM, Zhang MX, Zhang K, Chen YG, Zhang C, Zhang Y. Angiotensin-(1-7) treatment mitigates right ventricular fibrosis as a distinctive feature of diabetic cardiomyopathy. Am J Physiol Heart Circ Physiol. 2015; 
308: H1007-19.

39. Hao P, Yang J, Liu Y, Zhang M, Zhang K, Gao F, Chen Y, Zhang C, Zhang Y. Combination of angiotensin-(1-7) with perindopril is better than single therapy in ameliorating diabetic cardiomyopathy. Sci Rep. 2015; 5: 8794.

40. Floras JS. Sympathetic nervous system activation in human heart failure: clinical implications of an updated model. Journal of the American College of Cardiology. 2009; 54: 375-85.

41. Linz D, Schotten U, Neuberger HR, Bohm M, and Wirth $\mathrm{K}$. Negative tracheal pressure during obstructive respiratory events promotes atrial fibrillation by vagal activation. Heart Rhythm. 2011; 8: 1436-1443.

42. Bradley TD. CPAP should be used for central sleep apnea in congestive heart failure patients. J Clin Sleep Med. 2006; 2: 394-8.

43. Fava C, Dorigoni S, Dalle Vedove F, Danese E, Montagnana M, Guidi GC, Narkiewicz K, and Minuz P. Effect of CPAP on blood pressure in patients with OSA/ hypopnea a systematic review and meta-analysis. Chest. 2014; 145: 762-71.

44. Sharma BK, Bakker JP, McSharry DG, Desai AS, Javaheri $\mathrm{S}$, and Malhotra A. Adaptive servoventilation for treatment of sleep-disordered breathing in heart failure: a systematic review and meta-analysis. Chest. 2012; 142: 1211-21.

45. Janssens JP, Derivaz S, Breitenstein E, De Muralt B, Fitting JW, Chevrolet JC, and Rochat T. Changing patterns in longterm noninvasive ventilation: a 7-year prospective study in the Geneva Lake area. Chest. 2003; 123: 67-79.

46. Solomon SD, Anavekar N, Skali H, McMurray JJ, Swedberg K, Yusuf S, Granger CB, Michelson EL, Wang D, Pocock S, and Pfeffer MA. Influence of ejection fraction on cardiovascular outcomes in a broad spectrum of heart failure patients. Circulation. 2005; 112: 3738-44.
47. Philip-Joet FF, Paganelli FF, Dutau HL, and Saadjian AY. Hemodynamic effects of bilevel nasal positive airway pressure ventilation in patients with heart failure. Respiration. 1999; 66: 136-43.

48. Yoshida M, Kadokami T, Momii H, Hayashi A, Urashi T, Narita S, Kawamura N, and Ando S. Enhancement of cardiac performance by bilevel positive airway pressure ventilation in heart failure. Journal of cardiac failure. 2012; 18: 912-8.

49. Kohnlein T, Welte T, Tan LB, and Elliott MW. Assisted ventilation for heart failure patients with Cheyne-Stokes respiration. The European respiratory journal. 2002; 20: 934-41.

50. Dohi T, Kasai T, Narui K, Ishiwata S, Ohno M, Yamaguchi $\mathrm{T}$, and Momomura S. Bi-level positive airway pressure ventilation for treating heart failure with central sleep apnea that is unresponsive to continuous positive airway pressure. Circ J. 2008; 72: 1100-5.

51. Bitter T, Westerheide N, Faber L, Hering D, Prinz C, Langer C, Horstkotte D, and Oldenburg O. Adaptive servoventilation in diastolic heart failure and CheyneStokes respiration. The European respiratory journal. 2010; 36: 385-92.

52. Zoccali C, Mallamaci F, and Tripepi G. Nocturnal hypoxemia predicts incident cardiovascular complications in dialysis patients. J Am Soc Nephrol. 2002; 13: 729-33.

53. Hao PP, Zhang MX, Li RJ, Yang JM, Wang JL, Chen YG, and Zhang Y. Clopidogrel 150 vs. $75 \mathrm{mg}$ day(-1) in patients undergoing percutaneous coronary intervention: a metaanalysis. J Thromb Haemost. 2011; 9: 627-37. 